\title{
Metabolism and Disposition of Tribendimidine and Its Metabolites in Healthy Chinese Volunteers
}

\author{
Guiyan Yuan, ${ }_{1}^{1}$ Jie Xu, ${ }^{2}$ Tingting $Q u,{ }^{3}$ Benjie Wang, ${ }^{1}$ Rui Zhang, ${ }^{1}$ Chunmin Wei ${ }^{1}$ \\ and Ruichen Guo ${ }^{1}$ \\ 1 Institute of Clinical Pharmacology, Qilu Hospital of Shandong University, Jinan, China \\ 2 Department of Bioengineering, Zibo Vocational Institute, Zibo, China \\ 3 Decheng Branch of Dezhou Food and Drug Administration, Dezhou, China
}

Background: Tribendimidine is a new anthelmintic agent synthesized by Chinese scientists. It is a broad spectrum agent with high activity against parasites. However, its disposition and metabolism remain unknown.

Objective: To investigate the metabolism, disposition, and metabolites of tribendimidine in healthy human volunteers.

Methods: Twelve healthy Chinese volunteers were chosen after clinical assessment of health status and laboratory tests. They received single oral doses of tribendimidine $400 \mathrm{mg}$ enteric-coated tablets. Blood and urine samples were collected at scheduled timepoints. Samples were qualitatively and quantitatively analyzed by liquid chromatography-mass spectrometric (LC-MS) and high performance liquid chromatography (HPLC) methods, respectively.

Results: Tribendimidine was rapidly and completely broken down to $p$-(1-dimethylamino ethylimino) aniline (dADT) and terephthalaldehyde (TPAL). Furthermore, dADT was partially transformed to acetylated dADT, and TPAL completely transformed to terephalic acid (TPAC). The main pharmacokinetic parameters $( \pm \mathrm{SD})$ of $\mathrm{dADT}$ were as follows: elimination half life $\left(\mathrm{t}_{1 / 2}\right) 4.74 \pm 1.80 \mathrm{~h}$; elimination rate constant $\left(\mathrm{K}_{\mathrm{e}}\right) 0.16 \pm 0.06 \mathrm{~h}^{-1}$; apparent volume of distribution $(\mathrm{Vd} / \mathrm{F}) 12.23 \pm 8.69 \mathrm{~L} \bullet \mathrm{kg}^{-1}$; apparent total clearance of the drug from plasma (CL/F) $1.63 \pm 0.58 \mathrm{~L} \bullet \mathrm{h}^{-1} \bullet \mathrm{kg}^{-1}$; area under the plasma concentration-time curve (AUC) from time 0 to time 24 hours $\left(\mathrm{AUC}_{24}\right) 4.29 \pm 1.88 \mu \mathrm{g} \bullet \mathrm{mL}^{-1} \bullet \mathrm{h}$; AUC from time zero to infinity (AUC $\mathrm{A}_{\infty}$ ) $4.45 \pm 1.81 \mu \mathrm{g} \bullet \mathrm{mL}^{-1} \bullet \mathrm{h}$; maximum plasma drug concentration $\left(\mathrm{C}_{\max }\right)$ $0.64 \pm 0.27 \mu \mathrm{g} \bullet \mathrm{mL}^{-1}$; and time to $\mathrm{C}_{\max }\left(\mathrm{t}_{\max }\right) 4.20 \pm 0.71 \mathrm{~h}$. A total of $35.28 \%$ $\mathrm{dADT}$ and $28.50 \%$ TPAC were excreted through the urine within 24 hours after tribendimidine administration.

Conclusion: These results reveal the disposition, metabolism, and main metabolites of tribendimidine in healthy Chinese volunteers. 


\section{Introduction}

Tribendimidine, $\mathrm{N}, \mathrm{N}^{\prime}$-bis[4'-(1-dimethyl amino ethylidene amino)phenyll-1,4-phenylene-dimethylidyne amine, is a new and effective anthelmintic agent, with broad spectrum activity against helminthes. It is highly active against Ascaris lumbricoides and Necator americanus without mutagenic and clastogenic effects compared with other anthelmintic agents. ${ }^{[1]}$ Worldwide, more than 1221 million people are infected with Ascaris lumbricoides (the most common intestinal nematode), 795 million people with Trichuris triciura, and 740 million people with hookworms. ${ }^{[2]}$ Tribendimidine is promising because of its safety profile, broad spectrum, and high levels of activity.

In clinical and pharmacodynamic studies, Yueyi et al. ${ }^{[3]}$ and Kuiyang et al. ${ }^{[4]}$ showed that tribendimidine was highly active against hookworm and Ascaris. The adverse effects of tribendimidine were very mild and transient. Zhongxing and Yixin $^{[5]}$ compared the therapeutic and adverse effects of single or combination doses of tribendimidine and ivermectin against human nematodiasis. It was indicated that tribendimidine combined with ivermectin had the highest cure rate, suggesting the existence of synergism. Shuhua et al. ${ }^{[6]}$ assessed the efficacy of artemether, artesunate, praziquantel, and tribendimidine against different stages of Clonorchis sinensis in vivo, and found that the artemisinins and tribendimidine possess important clonorchicidal properties.

Few studies have focused on the metabolism and pharmacokinetic profiles of tribendimidine in humans. In vitro, tribendimidine is unstable and quickly broken down to $p$-(1-dimethylamino ethylimino) aniline (dADT) and terephthalaldehyde (TPAL) in acidic buffer, human blank plasma, and urine. ${ }^{[7]}$ dADT was demonstrated to be present in human plasma and urine after oral administration of tribendimidine enteric-coated tablets; however, only $40 \%$ of the original dose was recovered, indicating that other metabolites may be produced. TPAL was not detected in human plasma, urine, or feces, but its metabolite, terephalic acid (TPAC), was present in human urine. dADT and TPAC were detected in human plasma and urine using liquid chromatographymass spectrometric (LC-MS) and high performance liquid chromatography (HPLC) methods. ${ }^{[7,8]}$ The disposition of tribendimidine in vivo can be identified by these same methods. In the present study, we aimed to identify the distribution, metabolism, and metabolites of tribendimidine in humans using qualitative and quantitative analyses.

\section{Materials and Methods}

\section{Chemicals and Reagents}

Tribendimidine, dADT standard $(>99 \%)$ and tribendimidine enteric-coated tablets $(200 \mathrm{mg}$, No. 0505226) were provided by Xinhua Pharmaceutical Co. Ltd. (Zibo, China). TPAL and TPAC were purchased from Sinopharm Chemical Reagent Co. Ltd. (Shanghai, China). Mirtazapine standard ( $>99 \%)$ was provided by Kexinwei Pharmacy Research Company (Jinan, China). Ferulaic acid was provided by the Chinese National Institute for the Control of Pharmaceutical and Biological Products (Beijing, China). HPLC-grade acetonitrile and methanol were purchased from J.T.Baker (Phillipsburg, NJ, USA). Glacial acetic acid and triethylamine were purchased from Tedia Company (Fairfield, CT, USA).

\section{Instruments}

The LC-MS system equipped with electrospray ionization (ESI) source, HPLC pump, and autosampler (Agilent, Santa Clara, CA, USA) was used for metabolism analysis and dADT detection in human plasma samples. The Agilent HPLC and Waters HPLC systems (Milford, MA, USA) were used to determine dADT and TPAC levels in human urine samples.

\section{Chromatography and Mass Spectra Conditions}

The LC-MS method was used to examine dADT levels in human plasma and feces. The separation was performed using a Hypersil $\mathrm{C}_{18}$ column $(250 \times 4.6 \mathrm{~mm}$ inner diameter [ID], $5 \mu \mathrm{m})$ with mobile phase containing ammonium acetate $10 \mathrm{mmol} / \mathrm{L}$ (containing $0.1 \%$ triethylamine) : acetonitrile $(20: 80, v / v)$ at $25^{\circ} \mathrm{C}$. Flow rate was 
$1.0 \mathrm{~mL} \bullet \mathrm{min}^{-1}$. The ESI source was set to positive ion mode with capillary voltage $4000 \mathrm{~V}$, desolvation gas (nitrogen) heated at $350^{\circ} \mathrm{C}\left(11.0 \mathrm{~L} \bullet \mathrm{min}^{-1}\right)$, nebulizer pressure $50 \mathrm{psi}$, and fragment voltage $90 \mathrm{~V}$. Quantification was performed with selected ion monitoring (SIM) of mass-to-charge ratio $(\mathrm{m} / \mathrm{z}) 178.1$ for $\mathrm{dADT}$.

dADT and TPAC in human urine were examined using the HPLC method. dADT was separated through an Extend $\mathrm{C}_{18}$ column $(250 \times$ $4.6 \mathrm{~mm} \mathrm{ID}, 5 \mu \mathrm{m})$ by isocratic elution using methanol: acetonitrile: water: triethylamine (35: $35: 30: 0.2, v / v / v / v)$ at $0.7 \mathrm{~mL} \bullet \mathrm{min}^{-1}$. Mirtazapine was used as the internal standard and UV detection was at $249 \mathrm{~nm}$. TPAC was separated through an Ultimate $\mathrm{XB} \mathrm{C}_{18}$ column $(200 \times 4.6 \mathrm{~mm} \mathrm{ID,}$ $5 \mu \mathrm{m})$ by isocratic elution with methanol:1\% glacial acetic acid $(35: 65, v / v)$ at $0.8 \mathrm{~mL} \bullet \mathrm{min}^{-1}$. Ferulaic acid was used as the internal standard and UV detection was at $240 \mathrm{~nm}$.

The LC-MS method was used to analyze the metabolite of tribendimidine in urine with an Agilent Extend $\mathrm{C}_{18}$ column $(250 \mathrm{~mm} \times 4.6 \mathrm{~mm}$ ID, $5 \mu \mathrm{m})$ at $25^{\circ} \mathrm{C}$. Isocratic elution of the analyte was performed with mobile phase (acetonitrile: methanol: water: triethylamine $[35: 35: 30: 0.2$, $v / v / v / v])$ at $1.0 \mathrm{~mL} \bullet \mathrm{min}^{-1}$. The analyte was detected and analyzed with ESI ion source in both positive ion mode and full scan mode. The molecular weight ranged from 110 to 600 . The detection conditions of capillary voltage, source temperature, drying gas flow, and nebulizer pressure were $4000 \mathrm{~V}, 350^{\circ} \mathrm{C}, 11.0 \mathrm{~L} \bullet \mathrm{min}^{-1}$, and 50 psi, respectively.

\section{Method Validation and Sample Preparation}

dADT $\left(1.0 \mathrm{mg} \bullet \mathrm{mL}^{-1}\right)$ stock solution was prepared and diluted in ethanol for the working solutions. Linearity was assessed ranging from 0.5 to $1000 \mathrm{ng} \bullet \mathrm{mL}^{-1}$ in plasma and from 5 to $500 \mu \mathrm{g} \bullet \mathrm{mL}^{-1}$ in urine. Similarly, TPAC stock solution $\left(2.0 \mathrm{mg} \bullet \mathrm{mL}^{-1}\right)$ was prepared and diluted in $1 \%$ sodium hydroxide for the working solutions. Linearity was assessed ranging from 1 to $400 \mu \mathrm{g} \bullet \mathrm{mL}^{-1}$ in urine.

A calibration curve was constructed on the basis of peak area and this was analyzed using weighted linear regression. The lower limit of quantification (LLOQ) was defined as the lowest concentration to be produced at least five times with acceptable precision (relative standard deviation $[\mathrm{RSD}]<20 \%)$ and accuracy $(80-120 \%$ of nominal concentration). Intra- and inter-day precision and accuracy were determined by analyzing spiked samples with low, medium, or high concentrations for 3 days, and five replicates were applied. Three aliquots of the spiked samples at low, medium, or high concentration were stored for the stability studies of dADT and TPAC.

A total of $0.5 \mathrm{~mL}$ of plasma, $50 \mu \mathrm{L}$ of sodium hydroxide $(5 \mathrm{~mol} / \mathrm{L})$ and $0.3 \mathrm{~mL}$ of acetonitrile were added to a $1.5 \mathrm{~mL}$ polypropylene centrifuge tube; this was vortex-mixed for 1 minute, and then centrifuged at $11132 \mathrm{~g}$ (revolutions per minute) for 5 minutes. The supernatant was transferred into another $1.5 \mathrm{~mL}$ polypropylene centrifuge tube that contained $50-60 \mathrm{mg}$ sodium chloride; this was vortex-mixed for 30 seconds, incubated for 10 minutes at room temperature, and then centrifuged for 5 minutes at $11132 \mathrm{~g}$. A total of $5 \mu \mathrm{L}$ of the final supernatant was injected for analysis. Urine samples were diluted and then analyzed without disposition after adding the internal standard (mirtazapine for dADT and ferulaic acid for TPAC).

\section{Study Design}

Twelve healthy Chinese volunteers (six men and six women, aged 23-27 years) were screened after clinical assessment of health status and laboratory tests. Informed consents were signed before starting the experiments. The protocol was approved by the Ethic Committee of Qilu Hospital, and was conducted in accordance with the Declaration of Helsinki.

The volunteers fasted for 10 hours. After oral administration of tribendimidine enteric-coated tablets $(400 \mathrm{mg}), 4 \mathrm{~mL}$ of blood was collected before (0 hours), and 0.5, 1, 2, 2.5, 3, 3.5, 4, 4.5, 5, $6,8,12$, and 24 hours after administration, and a liquor of urine samples were collected at time zero (blank sample), 0-2, 2-4, 4-6, 6-8, 8-12, and 12-24 hours after administration. Plasma was separated, collected, and stored at $-20^{\circ} \mathrm{C}$ for 
a

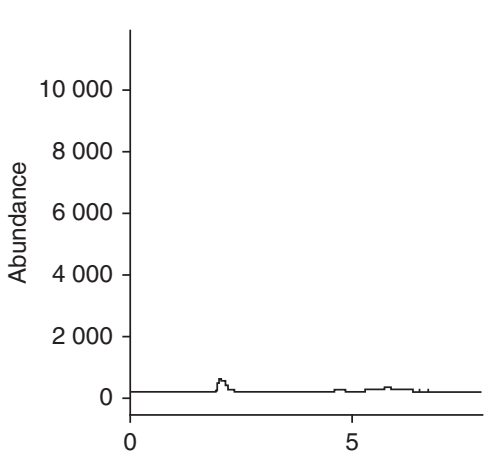

b

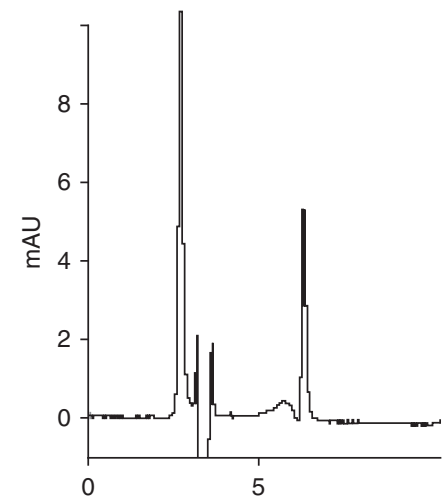

c

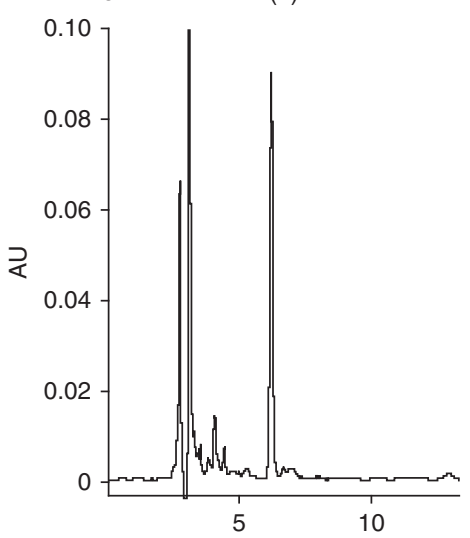

(2)

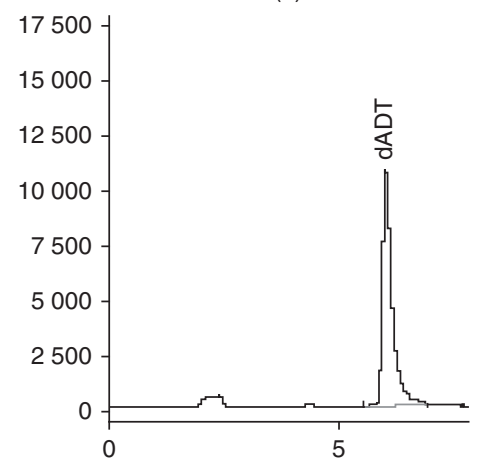

(2)

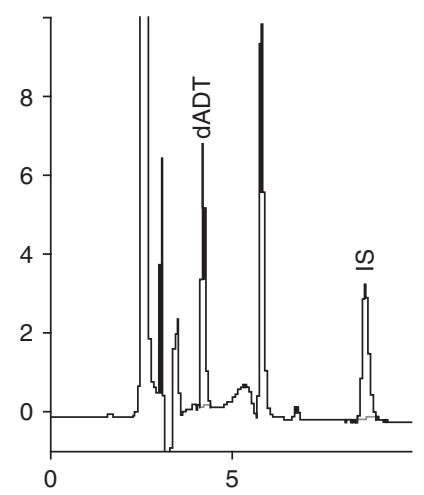

(2)



(3)

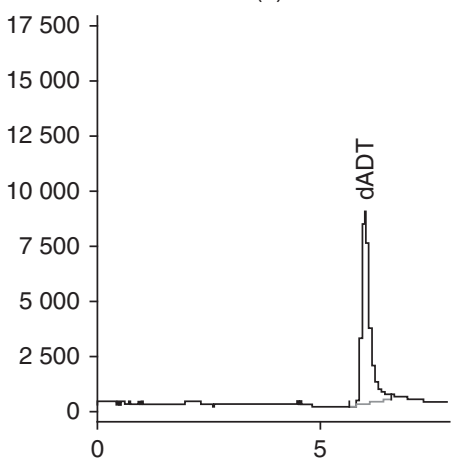

(3)

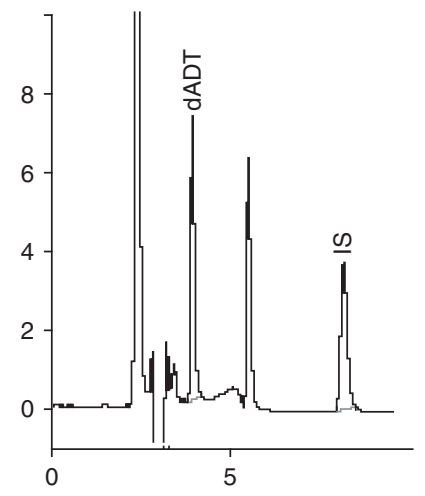

(3)

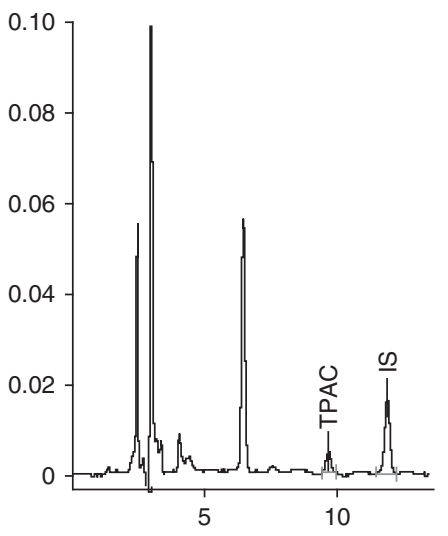

Fig. 1. The typical chromatograms of (a) blank plasma (1), plasma sample spiked with $p$-(1-dimethylamino ethylimino) aniline [dADT] (2), and plasma sample from a volunteer 1 hour after oral administration of tribendimidine (3); (b) blank urine (1), urine sample spiked with dADT and mirtazapine [internal standard; IS] (2), and urine sample from a volunteer 4 hours after oral administration of tribendimidine spiked with IS (3); and (c) blank urine (1), urine sample spiked with terephalic acid (TPAC) and ferulaic acid [IS] (2), and urine sample from a volunteer 4 hours after oral administration of tribendimidine spiked with IS (3). $\mathbf{A U}=$ absorb unit; $\mathbf{m A U}=$ mini-absorb unit. 
Table I. Precision (relative standard deviation [RSD]) and accuracy for the determination of $p$-(1-dimethylamino ethylimino) aniline (dADT) and terephalic acid (TPAC) in human plasma and urine

\begin{tabular}{lllll}
\hline Variable & Concentration & \multicolumn{2}{l}{ RSD $(\%)$} & $\begin{array}{l}\text { Accuracy (\% of nominal } \\
\text { concentration) }\end{array}$ \\
\cline { 5 - 5 } dADT & intra-day & inter-day & 97.72 \\
Plasma & $1 \mathrm{ng} \bullet \mathrm{mL}^{-1}$ & 2.93 & 4.88 & 96.78 \\
& $50 \mathrm{ng} \bullet \mathrm{mL}^{-1}$ & 1.22 & 1.74 & 97.12 \\
& $800 \mathrm{ng} \bullet \mathrm{mL}^{-1}$ & 1.86 & 3.22 & 99.82 \\
Urine & $10 \mu \mathrm{g} \bullet \mathrm{mL}^{-1}$ & 2.98 & 2.66 & 99.26 \\
& $50 \mu \mathrm{g} \bullet \mathrm{mL}^{-1}$ & 0.59 & 2.52 & 97.03 \\
TPAC & $400 \mu \mathrm{g} \bullet \mathrm{mL}^{-1}$ & 1.37 & 2.79 & 105.99 \\
Urine & & & & 107.40 \\
& $3 \mu \mathrm{g} \bullet \mathrm{mL}^{-1}$ & 5.37 & 6.24 & 108.49 \\
\hline
\end{tabular}

analysis. The Drug and Statistic (DAS, version $2.0)^{[9]}$ program was used to fit the compartmental model of dADT and calculate the main pharmacokinetic parameters as follows: elimination half-life $\left(\mathrm{t}_{1 / 2}\right)$, elimination rate constant $\left(\mathrm{K}_{\mathrm{e}}\right)$, area under the plasma concentration-time curve from time 0 to 24 hours $\left(\mathrm{AUC}_{24}\right)$, area under the plasma concentration-time curve from time zero to infinity $\left(\mathrm{AUC}_{\infty}\right)$, apparent total clearance of the drug from plasma $(\mathrm{CL} / \mathrm{F})$, and apparent volume of distribution $(\mathrm{Vd} / \mathrm{F})$. The maximum plasma drug concentration $\left(\mathrm{C}_{\max }\right)$ and the time to reach $\mathrm{C}_{\max }\left(\mathrm{t}_{\max }\right)$ were also observed. Accumulated excretion rates of $\mathrm{AADT}$ and TPAC in urine were obtained by the following equation: accumulated excretion rate $=$ accumulated excretion amount/ time $\times 100 \%$.

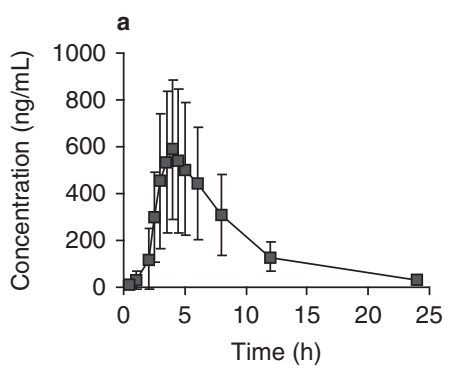

Chromatograms of blank urine samples were compared with those of urine samples collected after oral administration of tribendimidine enteric-coated tablets. The natures of the metabolites were determined by their standard and molecular weight.

\section{Results}

\section{Validation of Analytical Methods}

The typical chromatograms of plasma and diluted urine are shown in figure 1. No interferences were found in analyzed plasma and urine samples. The retention time of dADT in plasma was approximately 6.08 minutes. The retention times of dADT and its internal standard in urine were 4.10 and 8.76 minutes, respectively. The

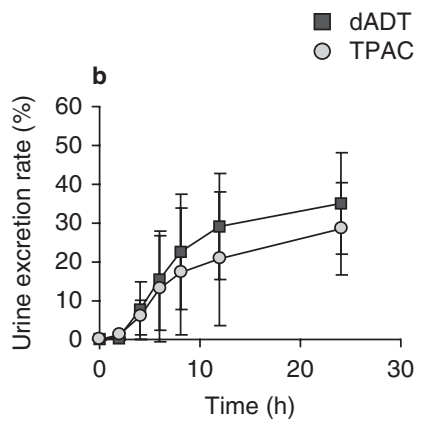

Fig. 2. (a) The plasma concentration vs time profile of $p$-(1-dimethylamino ethylimino) aniline (dADT) $[n=12]$ and (b) the urine excretion rate vs time curves of dADT and terephalic acid (TPAC) [ $n=6]$ after oral administration of tribendimidine $400 \mathrm{mg}$ enteric-coated tablets. 

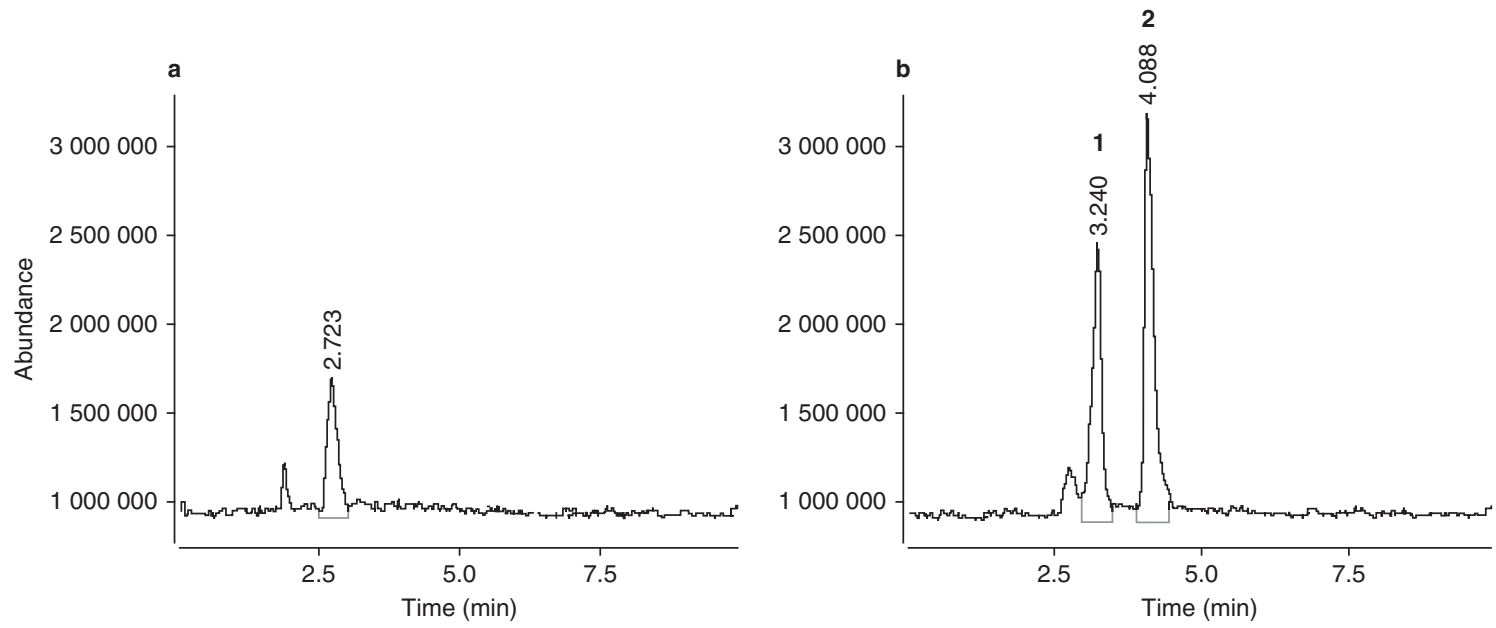

Fig. 3. Chromatograms of (a) blank urine and (b) urine collected 4 hours after administration of tribendimidine. Peaks 1 and 2 in (b) correspond to the peak retention times of acylated $p$-(1-dimethylamino ethylimino) aniline (dADT) and dADT, respectively (see figure 4 for more detailed analysis).

retention times of TPAC and its internal standard in urine were 9.86 and 12.06 minutes, respectively.

The calibration curves of dADT were linear above the concentration ranges in plasma $(n=5)$ and urine $(\mathrm{n}=5)$ with the regression equations (weight $=1 / X^{2}$ ), which were $\mathrm{Y}=14767.7001 X+$ 783.85047 for plasma and $\mathrm{Y}=4.283 X+0.001$ for urine, and the correlation coefficients were 0.999 . The LLOQ of dADT was $0.5 \mathrm{ng} \bullet \mathrm{mL}^{-1}$ in plasma $(\mathrm{n}=5)$ and $5 \mu \mathrm{g} \bullet \mathrm{mL}^{-1}$ in urine $(\mathrm{n}=5)$.

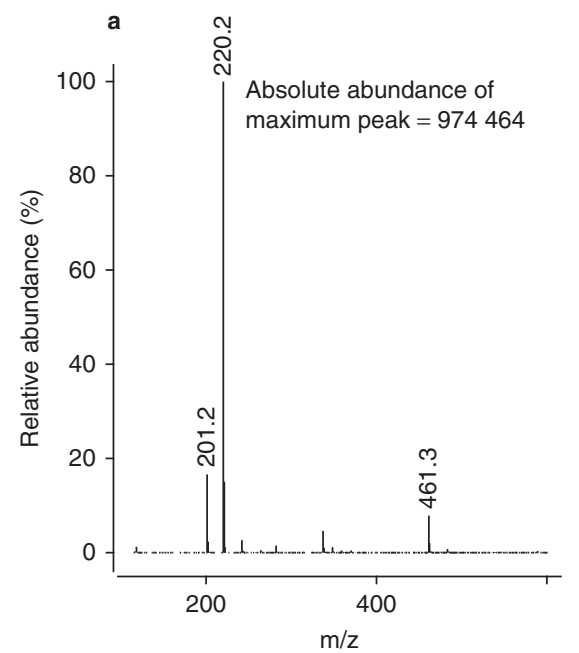

The calibration curve of TPAC was linear above the concentration range in urine. The regression equation was $\mathrm{Y}=0.0268 X-0.00147$ with a correlation coefficient of 0.9954 . The LLOQ of TPAC was $1 \mu \mathrm{g} \bullet \mathrm{mL}^{-1}$ in urine $(\mathrm{n}=5)$.

The intra- and inter-assay precision and accuracy of $\mathrm{dADT}$ and TPAC were acceptable for the analysis. All data were obtained from five replicates on 3 consecutive days, and are shown in table I.

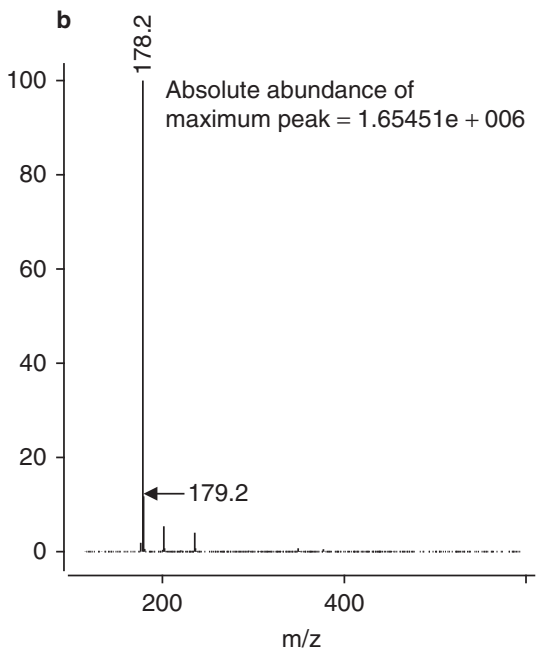

Fig. 4. Mass spectrum of (a) acetylated $p$-(1-dimethylamino ethylimino) aniline (dADT) and (b) $d A D T . ~ m / z=$ mass-to-charge ratio. 


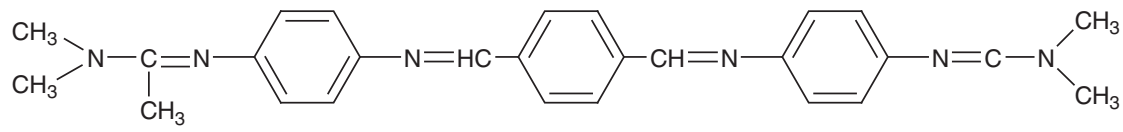

Tribendimidine

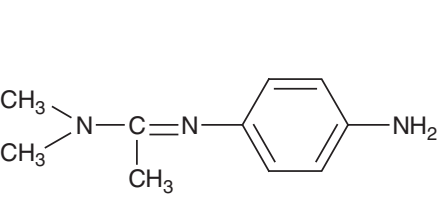

dADT (35.28\% excreted through urine)

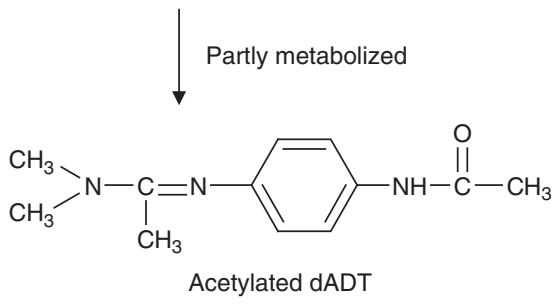

Low pH or enzyme

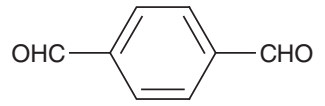

TPAL (undetected in urine) Completely metabolized

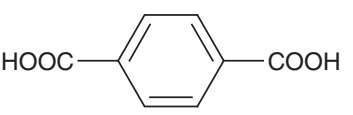

TPAC (28.50\% excreted through urine)

Fig. 5. The breakdown of tribendimidine in the human body. $\mathbf{d A D T}=p$-(1-dimethylamino ethylimino) aniline; TPAC $=$ terephalic acid; TPAL $=$ terephthalaldehyde.

The stability of dADT in human plasma and urine, and TPAC in human urine were investigated under different storage and process conditions. The analyte was assayed with three concentrations. dADT was stable after being frozen for 7 days at $-20^{\circ} \mathrm{C}(90.00-94.70 \%$ of the initial value in plasma and $97.84-99.88 \%$ in urine), and stable after two freeze-thaw cycles $\left(-20^{\circ} \mathrm{C} /\right.$ room temperature) [92.35-100.68\% of the initial value in plasma and $98.64-99.78 \%$ in urine]. TPAC was stable after being frozen for 7 days at $-20^{\circ} \mathrm{C}$ (95.32-99.70\% of the initial value) or two freezethaw cycles $\left(-20^{\circ} \mathrm{C} /\right.$ room temperature) [96.75$102.13 \%$ of the initial value].

\section{Metabolism and Disposition of Tribendimidine and Its Metabolites}

The plasma concentration and urine excretion rate versus time curves of dADT and TPAC in human plasma and urine are shown in figure 2 . The kinetics of dADT fit a one-compartmental model. The main pharmacokinetic parameters were as follows: $\mathrm{t}_{1 / 2} 4.74 \pm 1.80 \mathrm{~h} ; \mathrm{K}_{\mathrm{e}} 0.16 \pm 0.06 \mathrm{~h}^{-1} ; \mathrm{Vd} / \mathrm{F}$ $12.23 \pm 8.69 \mathrm{~L} \bullet \mathrm{kg}^{-1} ; \mathrm{CL} / \mathrm{F} 1.63 \pm 0.58 \mathrm{~L} \bullet \mathrm{h}^{-1} \bullet \mathrm{kg}^{-1}$;
$\mathrm{AUC}_{24} 4.29 \pm 1.88 \mu \mathrm{g} \bullet \mathrm{mL}^{-1} \bullet \mathrm{h} ; \mathrm{AUC}_{\infty} 4.45 \pm$ $1.81 \mu \mathrm{g} \bullet \mathrm{mL}^{-1} \bullet \mathrm{h} ; \quad \mathrm{C}_{\max } \quad 0.64 \pm 0.27 \mu \mathrm{g} \bullet \mathrm{mL}^{-1}$; and $t_{\max } 4.20 \pm 0.71 \mathrm{~h}$. Accumulated excretion rates of dADT and TPAC were $35.28 \pm 13.00 \%$ and $28.50 \pm 11.92 \%$ in urine, respectively.

The chromatograms of blank urine samples and urine samples collected after oral administration of tribendimidine are shown in figure 3. Two peaks of retention time, 3.2 minutes and 4.1 minutes, were validated by LC-MS. Peak 1 (protonated molecular ion $\left.[\mathrm{M}+\mathrm{H}]^{+}, 220.2\right)$ and peak $2\left([\mathrm{M}+\mathrm{H}]^{+}, 178.2\right)$ are shown in figures $4 \mathrm{a}$ and $4 \mathrm{~b}$, respectively. Peak 2 is dADT and peak 1 is the acetylated metabolite of dADT based on their molecular weight and standard.

\section{Discussion}

In this study, the LC-MS and HPLC methods for determination of AADT and TPAC in human plasma and urine were established. The high sensitivity for dADT was obtained using the electrospray ion source and positive selective ion monitoring mode. The mobile phase for the LCMS method was optimized by comparing various 
percentages of methanol:ammonium acetate $10 \mathrm{mmol} / \mathrm{L}$ or acetonitrile: ammonium acetate $10 \mathrm{mmol} / \mathrm{L}$ to improve separation and to enhance sensitivity. Use of acetonitrile and triethylamine, instead of methanol, allowed appropriate retention time and sharp peak shape, respectively. No endogenous interferences were found under the optimized LC-MS conditions.

The results indicated that tribendimidine was immediately broken down to dADT and TPAL after oral administration of enteric-coated tablets. dADT in plasma can be used to evaluate the pharmacokinetic behavior of tribendimidine in vivo after its oral administration. The metabolite TPAL was also not detected in either urine or plasma, because it was quickly metabolized to a more stable metabolite (TPAC), which was found in urine. dADT was further metabolized to an acetylated form by acetyltransferase, as shown in figure 5.

dADT is the major metabolite of tribendimidine. However, so far, there have been no studies to demonstrate its anti-parasitic activity. The activity of dADT, degree of acetylation, and activity of acetylated dADT are expected to be identified in future studies.

\section{Conclusion}

Specific, sensitive, and rapid methods were developed to determine AADT and TPAC, and to investigate the disposition and metabolism of tribendimidine in human plasma and urine. Our data suggest that tribendimidine is rapidly broken down to dADT and TPAL. Furthermore, dADT was partially transformed to acetylated dADT, and TPAL was completely transformed to TPAC. The anti-parasitic activity of dADT and its ace- tylated metabolite, and the degree of its acetylation need further investigation.

\section{Acknowledgments}

No sources of funding were used to assist in the preparation of this article. The authors have no conflicts of interest to declare that are directly relevant to the content of this article.

\section{References}

1. Shuhua X, Huiming W, Tanner M, et al. Tribendimidine: a promising, safe and broad-spectrum anthelmintic agent from China. Acta Trop 2005; 94: 1-14

2. De Silva NR, Brooker S, Hotez PJ, et al. Soli-transmitted helminth infections: updating the global picture. Trends Parasitol 2003; 19: 547-51

3. Yueyi F, Wenjia L, Qiming Z, et al. Study on the efficacy of tribendimindine for treatment of intestinal nematode infections. Chin J Schisto Control 2002; 14: 125-7

4. Kuiyang Z, Zhongxing W, Yisheng L, et al. Clinical observations on therapeutic effect of tribendimidine against hookworm, Ascaris, Trichuris and Enterobius human infections. J Fract Parasit Dis 2002; 10: 149-51

5. Zhongxin W, Yixin Q. Therapeutic effect of tribendimidine combined with ivermectin against human intestinal nematode infection. Parast Infec Dis 2003; 1: 59-61

6. Shuhua X, Jian X, Tanner M, et al. Artemether, artesunate, praziquantel and tribendimidine administered singly at different dosages against Clonorchis sinensis: a comparative in vivo study. Acta Tropica 2008; 106: 54-9

7. Guiyan Y, Benjie W, Chunmin W, et al. LC-MS determination of $p$-(1-dimethylamino ethylimino) aniline: a metabolite of tribendimidine in human plasma. Chromatographia 2008; 68: 139-42

8. Jie X, Guiyan Y, Chunmin W, et al. Determination of urinary tribendimidine metabolite-terephthalic acid by HPLC. J Shandong Univ Health Sci 2008; 46: 1016-9

9. Zhiyang C, Qingshan Z, Ruiyuan S. Functions of the DAS software for farmacological calculation. Chin Pharma. Chin J Clin Pharmacol Ther 2002; 7: 562-4

Correspondence: Dr Ruichen Guo, 107 Wenhua Xi Road, Jinan Shandong Province, 250012, China.

E-mail: grc7636@126.com 